\title{
A gravadora Chantecler e a música regional do Brasil
} EDUARDO VICENTE ${ }^{I}$

\section{Introdução}

$\mathrm{E}$

STE TEXTO ${ }^{1}$ visa apresentar a trajetória da gravadora Chantecler que, surgida em 1958, teve uma atuação bastante relevante no registro e difusão da música regional do país, especialmente da música sertaneja de São Paulo. Através do exemplo da Chantecler, bem como de outras gravadoras tradicionais paulistas como Continental e Copacabana, que serão brevemente mencionadas neste trabalho, tentarei evidenciar o importante papel desempenhado por empresas nacionais na história da indústria fonográfica do país, bem como a necessidade de um estudo mais aprofundado sobre as mesmas.

Inicialmente, será apresentada uma discussão sobre o desenvolvimento da indústria fonográfica no Brasil, em especial sobre o surgimento de suas primeiras gravadoras nacionais, que ocorreu a partir da associação entre empresários locais e grupos internacionais. A seguir, buscarei discutir as bases de um processo de estratificação do consumo musical que se desenvolveu aqui a partir da década de 1950. Então, será descrita a trajetória da gravadora Chantecler mediante um percurso em que busquei destacar alguns dos artistas e discos lançados pela empresa, bem como discutir as suas estratégias de atuação e o espaço que ocupou no cenário da indústria fonográfica brasileira.

A produção deste artigo deve muito à generosidade e à prodigiosa memória de Biaggio Baccarin, o "Dr. Brás", que foi diretor artístico da gravadora durante boa parte de sua existência e concedeu-nos dois longos depoimentos em 1999 e 2007. Sei que falo aqui em nome de inúmeros pesquisadores ao manifestar ao "Dr. Brás" meu reconhecimento e gratidão por sua contribuição às nossas pesquisas e à música popular brasileira.

\section{O início da indústria fonográfica no Brasil}

Creio que não há grandes discordâncias entre os pesquisadores acerca dos passos iniciais da indústria fonográfica no Brasil de que seu grande pioneiro foi Frederico Figner (1866-1947) que, natural da Boêmia, uma região da atual República Checa, emigrara para os Estados Unidos aos 15 anos em 1891 e começa a sua "peregrinação de propagandista do fonógrafo pela cidade de Belém do Pará" (Tinhorão, 1981, p.17). A partir de então, percorre o país fazendo exibições pagas de seus fonógrafos e vendendo equipamentos. Por volta de 1900, ele se instala no Rio de Janeiro onde abre a sua primeira loja, a Casa Edison, 
"loja importadora de produtos industrializados na qual vendia diversas sortes de novidades tecnológicas, como o kinetoscópio, lanternas, telefones, máquinas de escrever, além de máquinas falantes e seus discos" (Vicente; De Marchi, 2014, p.11).

A partir de 1902, Figner passa a atuar também na gravação de música popular e seus primeiros artistas contratados são os cantores de serenata Antônio da Costa Moreira, o Cadete, e Manuel Pedro dos Santos, o Baiano. Nesses primeiros trabalhos, foram registrados choros, lundus e modinhas, além de músicas diversas executadas pela recém-criada Banda do Corpo de Bombeiros (formada pelo maestro e compositor Anacleto de Medeiros em 1896) (Tinhorão, 1981, p.20-1).

As produções da Casa Edison eram feitas a partir de uma parceria com a empresa alemã Zonophone, que enviou um técnico ao país para as primeiras gravações: "As músicas eram gravadas aqui e os discos eram produzidos na Europa" (Francheschi, 2002, p.312). Em 1904, Figner torna-se representante exclusivo da gravadora Odeon no país, o que leva à implantação, por parte da empresa, da primeira fábrica de discos no Brasil, em 1913 (Giron, 1999, p.2), ainda na fase mecânica da indústria.

A partir de 1927, a tecnologia elétrica de gravação sonora passa a ser utilizada no país, permitindo aumentar a quantidade e a qualidade da produção de discos. Com o fim da vigência das patentes, grandes gravadoras internacionais começaram a competir por mercados periféricos através de investimentos diretos. Entre 1928 e 1930, algumas corporações abriram filiais no país como a Columbia Records, a RCA-Victor e a Brunswick, contando em alguns casos com o apoio de empresários locais. As vindas da Columbia Records e da RCA ao Brasil tiveram essa característica. No primeiro caso, a empresa se instalou por meio de uma associação com o empresário local Alberto Byington, que produzia equipamentos elétricos. Já a RCA associou-se à empresa Cássio Muniz S/A, que responderia até 1958 pela distribuição dos seus discos. Assim, ampliava-se a gama de competidores para a Odeon. (Vicente; De Marchi, 2014, p.12)

Creio que vale a pena refletir sobre a questão da parceria entre essas companhias internacionais e empreendedores locais, já que ela será, como veremos adiante, determinante para o surgimento de gravadoras nacionais como a Chantecler e a Continental. Empresários como Frederico Figner, Alberto Byington Jr. e Cássio Muniz, ao associarem-se a empresas internacionais, não apenas permitiram a essas ingressassem no país com um menor investimento e um maior conhecimento do seu mercado, como, mais importante, possibilitaram que elas atuassem não apenas através da impressão e distribuição dos discos que gravavam em suas matrizes europeias e norte-americanas, mas também produzindo música local. Assim, elas acabaram por desempenhar um papel fundamental na formação de carreiras e na formação de um hábito do consumo de repertório musical doméstico ainda nos momentos iniciais da indústria. 
Não resta dúvida de que uma importante ação no sentido da valorização da música popular brasileira e da cultura nacional foi desenvolvida, ainda que dentro de uma perspectiva autoritária, ao longo do primeiro governo Vargas (1930-1945). O papel marcante desempenhado nesse processo pela Rádio Nacional do Rio de Janeiro - emissora incorporada ao patrimônio da União em 1941 - também não pode ser diminuído, valendo destacar que toda uma geração inicial de grandes expoentes de nossa música popular, formada, entre outros, por Francisco Alves, Carmen e Aurora Miranda, Ary Barroso, Almirante, Orlando Silva e Carlos Galhardo - alcançou fama nacional através de seus transmissores.

De qualquer modo, é importante notar que a implantação das gravadoras citadas não só é anterior à chegada de Vargas ao poder, como possibilita um processo de profissionalização artística e organização da produção de música popular que certamente será bem aproveitado no rádio.

O caso da empresa de Byington é bastante significativo. Após a sua criação, ela imediatamente iniciou a gravação de discos de música brasileira que, assim como o catálogo internacional de sua matriz, eram lançados no país com o selo "Columbia do Brasil" (depoimento de Baccarin, 2007). Em 1943, a empresa não renovou seu contrato com a Columbia e criou seu próprio selo, $\mathrm{o}$ Continental, tornando-se a Continental Gravações Elétricas S/A, enquanto a Columbia passou a ser representada no Brasil pela Odeon. Entre os primeiros nomes lançados pela gravadora podem ser citados Batista Júnior, Jararaca e Ratinho, Paraguaçu, Noel Rosa e Zequinha de Abreu, entre outros. ${ }^{2}$ Entre as décadas de 1930 e 1950, a Continental lançou ainda artistas como Orlando Silva, Aracy de Almeida, Emilinha Borba, Anjos do Inferno, Sivuca, Dilermando Reis e Luis Bonfá. Passaram também pela gravadora nomes como Vadico, João de Barro, João Pernambuco, Garoto, Marlene, Dorival Caymmi, Lamartine Babo, Sílvio Caldas e Altamiro Carrilho, entre outros (Paiano, 1993, p.E3).

A Columbia do Brasil iria se tornar, a partir de sua relação com Cornélio Pires, a provável pioneira na gravação de música sertaneja no país. Gostaria de retomar esse episódio a partir do modo como ele é narrado por Ariovaldo Alves, sobrinho de Cornélio, em depoimento disponível no Acervo Aramis Millarch. ${ }^{3}$ Ariovaldo, que mais tarde se tornaria conhecido pelo nome artístico de Capitão Furtado, afirma ter atuado, ainda em 1928, como intérprete em uma reunião entre Cornélio Pires e Wallace Downey, cineasta e produtor norte-americano que representava a Columbia no Brasil e sugerira a Byington a parceria com a empresa.

Cornélio propõe a Downey a gravação de discos com as músicas e anedotas de sua Turma Caipira. Downey apresenta Cornélio a Alberto Byington Jr., afirmando que é a ele que caberá a decisão final. Byington recusa a proposta, argumentando que não haveria mercado para aquela produção. De qualquer modo, ele se dispõe a gravar os discos desde que Cornélio assuma os custos de sua produção e prensagem. 
Cornélio Pires não desiste e,

De forma independente, banca a confecção de cinco discos de 78rpm, na fábrica Colúmbia, e passa a divulgá-los nos programas de rádio. Em pouco tempo, vende estes discos e desperta no então presidente da fábrica Colúmbia, Byington Jr., o interesse em produzir mais discos desta cultura caipira. Cornélio aceita a oferta de Byington Jr. e produzem um total de quarenta e oito discos. (Correa, 2012, p.85)

Outros importantes nomes da música sertaneja seriam gravados pela Continental ainda em seus primeiros anos, como o já citado Paraguaçu e as duplas Jararaca e Ratinho e Tonico e Tinoco, entre outras. Segundo o depoimento de Biagio Baccarin (2007), a Continental também produziu curta-metragens com artistas da música sertaneja, mas esses acabaram se perdendo.

Ao apresentar o episódio da negociação entre Cornélio Pires e Alberto Byington Jr., com a recusa deste último, um autor como João Luiz Ferrete aponta para o que define como a "regra geral do preconceito" contra a música caipira por suas supostas deficiências artísticas (Ferrete, 1985, p.39), mas gostaria de examinar a questão sob a perspectiva da indústria.

A gravação e impressão de discos sob demanda não é uma atividade tradicional das gravadoras. Ao contrário, o controle sobre os meios de produção foi, historicamente, uma garantia de seu domínio sobre o mercado. Porém, provavelmente pelo sucesso da relação com Cornélio Pires, a Continental, além de um permanente vínculo com a música sertaneja, manteve, durante boa parte de sua existência, um departamento destinado especificamente a oferecer esse tipo de serviço a artistas independentes, denominado "Matéria Paga". O produtor musical Pena Schmidt, que atuou na empresa em diferentes períodos, chegou a dirigir esse departamento durante os anos 1970 e detalha seu funcionamento:

[...] você faz por encomenda, usa o know-how da empresa, os arranjadores, o carimbo de "disco da Continental" [...] Muita coisa, muito artista da Continental entrou como "matéria paga”, porque lá havia um enxame de produtores, que ouviam e falavam: “essa música é boa, vou dar pro fulano gravar”, pega a música de um matéria paga, dá pro outro [...] era o tempo todo assim e isso era feito de uma forma muito objetiva. O tal do sucesso era uma coisa perceptível e que passava na sua frente [... Esse lance da "matéria paga" era amazônico. Não contaminava, não chegava nada aqui, eram países diferentes, e a Continental ia lá em todos esses cantos. A Continental tinha essa característica que a separava das outras gravadoras. A gente falava: a Continental trabalha com o Brasil do lado de lá da Marginal Pinheiros, com o interior. As outras companhias trabalhavam da Marginal para cá, na direção do Rio de Janeiro. (Depoimento de Pena Schmidt, 2007)

\section{A estratificação do consumo musical}

Vale sublinhar a expressão de Pena Schmidt: "o Brasil do lado de lá da Marginal Pinheiros”. A metáfora traz a ideia de uma segregação, uma divisão 
entre as produções musicais de diferentes regiões do país. Uma hierarquização entre gêneros musicais e artistas que talvez seja uma das características mais marcantes da relação estabelecida pela indústria com a produção de nossa música popular. Abordar esse tema parece-me essencial para melhor compreendermos a atuação da Continental, da Chantecler e de outras gravadoras nacionais no contexto da indústria.

Ao falar sobre o cenário de produção e consumo cultural que se constituiu no Brasil a partir do pós-guerra, Renato Ortiz aponta para o surgimento de "um público que, sem se transformar em massa, define sociologicamente o potencial de expansão de atividades como o teatro, o cinema, a música e até mesmo a televisão [...] uma audiência específica, mas considerável, formada pelas camadas urbanas médias" (Ortiz, 1994, p.102).

Para Ortiz, será a presença desse público que possibilitará o surgimento de manifestações culturais mais sofisticadas, como o Teatro Brasileiro de Comédia - TBC (1948) -, a Companhia Cinematográfica Vera Cruz (1949), o Teatro de Arena (1953), o Cinema Novo (1955), a Bossa Nova (1958), o Teatro Oficina (1958), a MPB (por volta de 1965) e o Tropicalismo (1967). Em relação à MPB, Marcos Napolitano (2010, p.7) afirma que, além de ter permitido um extraordinário salto estético à nossa música popular, a sigla não apenas tornou-se "o epicentro de um amplo debate estético-ideológico ocorrido nos anos 60", como transformou-se "numa verdadeira instituição, fonte de legitimação na hierarquia sociocultural brasileira, com capacidade própria de absorver elementos que lhe são originalmente estranhos, como o rock e o jazz".

A importância cultural, artística e política da MPB é indiscutível e já foi apontada por inúmeros autores. O que gostaria de destacar, para o presente debate, é o seu papel no processo de reorganização da indústria fonográfica que então se verifica. Para tanto, vale ressaltar, das palavras de Napolitano, o papel da MPB enquanto "fonte de legitimação na hierarquia sociocultural". Para compreender melhor essa questão, gostaria de empreender uma breve recapitulação do debate sobre a música popular no país.

Ao discutir o tema, Arnaldo Contier (2004) destaca o papel central ocupado por Mário de Andrade nas décadas de 1920 e 1930. Segundo o autor, Mário de Andrade "defendia a pesquisa do folclore (música popular) como fonte de reflexão temática e técnica do compositor erudito preocupado, num primeiro momento, com a criação de uma música nacional" (Contier, 2004, p.1). Já na década de 1940, quando o desenvolvimento da radiodifusão levou a uma ampla divulgação da música popular, o debate se deslocou em grande medida para a música urbana e se realizou sob a égide do governo Vargas, onde a vocação disciplinadora e civilizatória do Estado se integrava às preocupações nacionalistas.

O samba, elevado à condição de música nacional, foi o objeto central desse debate. Visto por intelectuais orgânicos do regime como "feio, indecente, desarmônico e arrítmico", o samba deveria ser educado para se tornar a síntese de 
nossa nacionalidade. Opositores do samba-malandro, mais ligado à tradição dos morros, esses intelectuais viram o "samba-exaltação" - que teve na Aquarela do Brasil (Ary Barroso, 1940) seu exemplo de maior sucesso - como uma resposta às suas preocupações. Através dele, Pedro Anísio afirmava em 1943 que o samba havia se transformado em num "digno e elegante representante do espírito musical de nossa gente" (apud Saroldi; Moreira, 2005, p.49-50).

Após o final do Estado Novo e durante boa parte da década de 1950, o debate aparentemente arrefece. Esse período corresponde ao predomínio do rádio como principal veículo de comunicação do país, através do qual se consolidou toda uma geração de artistas como Marlene, Emilinha, Orlando Silva, Dircinha Batista, Linda Batista e Cauby Peixoto, entre outros. Vale observar que, nesse momento, o rádio não parecia estabelecer hierarquizações entre esses artistas ou entre os gêneros musicais aos quais estavam vinculados (Vicente; De Marchi; Gambaro, 2016).

Assim, embora o ingresso da música sertaneja no meio fonográfico possa ter enfrentado alguma resistência inicial, não me parece que maiores restrições ao gênero tenham se mantido até o final dos anos 1950. Como um possível exemplo podemos citar a rádio Gazeta de São Paulo, fundada em 1943. Apesar de sua forte vinculação com a música erudita, especialmente com a ópera contava com uma sala de concerto, um elenco próprio de cantores líricos e foi responsável pelas primeiras montagens de diversas óperas no país -, a emissora mantinha em sua grade horários dedicados à música popular, inclusive com programas, ao vivo e em horário nobre, voltados para a poesia sertaneja (Guerrini Jr., 2009, p.76).

A partir do final dos anos 1950, no entanto, tivemos o início do processo de hierarquização apontado por Napolitano. Em 1958 era lançado, pela gravadora nacional Festa, o LP Canções do amor demais, onde Elizeth Cardoso interpretava composições de Antônio Carlos Jobim e Vinícius de Moraes acompanhada ao violão por João Gilberto. Foi esse, como se sabe, o momento inaugural da Bossa Nova.

Ao propor uma concepção moderna de nossa nacionalidade musical, a Bossa Nova estabeleceu-se como um autêntico divisor de águas dentro do campo da música popular brasileira. Ela valorizou a temática urbana, a influência da música popular internacional, a sofisticação harmônica e melódica e as interpretações contidas como paradigmas dessa modernidade. Esse quadro, como sabemos, formou toda uma nova geração de artistas surgida nos anos subsequentes. Além disso, ele acompanhou importantes mudanças no mercado de bens simbólicos do país.

Nesse sentido, vale observar que a década de 1960 pode ser considerada o momento de efetiva substituição do rádio pela televisão como principal veículo de comunicação do país, e, como veremos mais adiante, de consolidação do disco de vinil como formato predominante da indústria fonográfica. A mu- 
dança no mainstream musical expressa essa situação. Toda a "nova geração" de artistas - Elis Regina, Jair Rodrigues, Roberto Carlos, Erasmo Carlos, Chico Buarque, Edu Lobo, Caetano Veloso e Gilberto Gil, entre muitos outros - surgiu ou atingiu a consagração a partir de programas televisivos como "O fino da bossa", "Jovem guarda", "Divino maravilhoso", e, principalmente, dos Festivais da Canção promovidos pelas emissoras de televisão Excelsior (1965) e Record (1966 a 1969). Simultaneamente, os "cantores do rádio", grandes astros das décadas anteriores, com pouco acesso e esses novos espaços de consagração, foram rapidamente eclipsados.

Essa hierarquização, com a consequente estratificação do consumo musical implicada no processo, teve um papel central na reorganização do setor fonográfico. Em seu contexto, tivemos não apenas a chegada de novas e importantes gravadoras internacionais ao país, como Philips (1960), Warner (1976) e Ariola (1979) (Vicente, 2014), como o surgimento de gravadoras enquanto braços fonográficos de emissoras de televisão, sendo o exemplo mais importante o da Som Livre, criada pela Rede Globo em 1971. A criação ou chegada ao Brasil dessas empresas pode ser associada ao extraordinário crescimento do mercado fonográfico então verificado, que elevou a produção de suportes musicais no país de 5,5 milhões de unidades, em 1966, para 52,6 milhões, em 1979, conforme dados da ABPD (Vicente, 2014, p.51).

Visando um mercado urbano de maior poder aquisitivo, as grandes gravadoras internacionais e conglomerados televisivos estabeleceram uma espécie de reserva de mercado em relação à nova geração de artistas. A gravadoras tradicionais como Continental, Copacabana (criada em 1948), e, como veremos, Chantecler, coube, a partir desse momento vincular-se cada vez mais ao mercado regional e a gêneros musicais voltados a um público de menor poder aquisitivo, como a música sertaneja.

Um importante sentido econômico dessa divisão de mercado estava no fato de que a MPB e a Jovem guarda, privilegiadas pela televisão e pelas gravadoras internacionais, tinham suas gravações comercializadas através de discos de maior valor, com boa margem de lucratividade. Já os segmentos mais populares vinculavam-se a discos de baixo preço e dependiam de um mercado consumidor bem mais vulnerável às flutuações da economia (Vicente, 2014, p.71-2).

Esse era o caso, por exemplo, da música sertaneja. Em 1979, diante da crise econômica que se acentuava, a Continental anunciou que pretendia se afastar da música sertaneja, pois, segundo afirmava seu diretor de marketing, Ariovaldo Piovezani, embora a Continental se considerasse responsável por $60 \%$ das vendas de discos do gênero, sua participação no mercado musical não ia além de $6 \%$. No entanto, Piovezani apontava que investir na MPB de "primeira linha" comportava um risco: "todo o esforço de procurar os produtos certos e cultivá-los pode esvair-se com uma oferta mais tentadora ao intérprete por uma gravadora forte, multinacional" (Gazeta Mercantil, 1979). 
Por essas questões, penso que seria possível afirmar que, no Brasil, empresas tradicionais de orientação única como a Continental e a Chantecler, entre outras, acabaram assumindo, a partir dessa divisão do mercado, um papel semelhante ao das gravadoras independentes em países centrais, ou seja, vincularam-se à formação de novos artistas e à prospecção de mercados de menor interesse econômico. Enquanto isso, as grandes gravadoras - como a Som Livre e as gravadoras internacionais aqui instaladas - impunham seu controle sobre o mercado mainstream.

Mas uma vez situado esse quadro geral, gostaria agora de me voltar para a trajetória da gravadora Chantecler.

\section{A Chantecler}

A gravadora Chantecler, assim como a Continental, tem sua origem na associação entre gravadoras internacionais e empreendedores nacionais discutida no início deste trabalho. Vimos então que a parceria entre Alberto Byington Jr. e a Columbia Records, em 1928, resultou no surgimento da Continental em 1943. No caso da Chantecler, seu surgimento, em 1956, foi fruto da já citada associação entre a subsidiária brasileira da gravadora norte-americana RCA-Victor e a Cássio Muniz S/A, contratada para a distribuição dos seus discos e equipamentos quase três décadas antes.

Segundo Biaggio Baccarin, a Cássio Muniz S/A, uma empresa paulistana, tinha sua sede na Praça da República, esquina com a Rua do Arouche, e contava com uma rede de representantes espalhada por todo o país. Além de toda a linha de discos e equipamentos eletrônicos da RCA-Victor (toca-discos, rádios e televisores), a empresa era representante de um vasto catálogo de produtos, em sua maioria importados, que incluía desde roupa íntima a veículos da General Motors e aviões da Cessna (Depoimento de Baccarin, 1999).

Ao decidir criar, em 1958, a sua própria rede de distribuição no país, a RCA, segundo Baccarin, sugeriu a Cássio Muniz que, como uma forma de compensação pelos serviços prestados, cria-se sua própria gravadora, valendo-se do know-how da empresa. O acordo era de que Cássio Muniz mantivesse, ainda por dois anos, a distribuição de discos da RCA, para poder consolidar seu próprio investimento na área (Depoimento de Baccarin, 1999). Nascia assim a gravadora Chantecler, nome derivado da expressão francesa chant clair (algo como "canto claro") e tendo a imagem de um galo como seu logotipo. Baccarin afirma ainda que, já no ano seguinte, a Chantecler abriu mão da distribuição da RCA devido ao grande sucesso de suas próprias produções.

É interessante observar que se nos apoiarmos nos relatos de Baccarin sobre o surgimento da Chantecler e da Continental, teremos um quadro de práticas empresariais um tanto incomuns no cenário atual. A RCA, segundo o relato, estimulou o surgimento de uma empresa concorrente como uma forma de agradecimento pelos serviços prestados. Já no caso da parceria entre Byington Jr. e a Columbia, o contrato parecia não prever qualquer restrição à empresa nacional 
na utilização do know-how da norte-americana, já que Byington Jr. pôde optar pela não renovação desse e passar a atuar no mercado fonográfico de forma autônoma. Assim, aparentemente as empresas internacionais não viam suas equivalentes brasileiras como reais concorrentes no mercado nacional até os anos 1950 , situação que, como vimos, iria se modificar de forma bastante significativa nos anos seguintes.

Segundo depoimento de Biaggio Baccarin (2007), no momento do surgimento da Chantecler, as principais gravadoras presentes em São Paulo e, portanto, as maiores concorrentes da empresa eram Columbia, Continental, Sinter, Copacabana, RCA e Odeon. A Sinter tinha sua sede no Rio de Janeiro e pertencia à família Pittigliani, porém, no momento em que a Chantecler era criada, seu nome havia sido alterado para CBD, Companhia Brasileira de Discos. Em 1960, ela foi adquirida pela Philips tornando-se a base para a implantação daquela empresa no país. Já a Copacabana foi criada no Rio de Janeiro em 1948, mas transferiu-se pouco tempo depois para São Paulo. Por ela gravaram nomes como Elizeth Cardoso, Ângela Maria, Agnaldo Rayol, Moacyr Franco e Wanderley Cardoso, além de muitos artistas da música sertaneja. Pela RCA, que, como vimos, se instalara no Brasil no final dos anos 1920, gravaram nomes como Vicente Celestino, Orlando Silva e Francisco Alves. A empresa foi vendida em 1987 para o conglomerado alemão Bertelsmann AG, tornando-se parte da BMG, Bertelsmann Music Group, que seria posteriormente absorvida pela Sony. A Odeon instalou, como vimos, a primeira fábrica de discos do Brasil, ainda em 1913. Ela seria adquirida pela britânica EMI em 1969, passando a denominar-se EMI-Odeon e, posteriormente, simplesmente EMI. Pela Odeon, gravaram em suas décadas iniciais nomes como Alvarenga e Ranchinho, Ataulfo Alves, Gastão Formenti, Francisco Alves e Mário Reis, entre outros.

Biaggio Baccarin aponta que a Chantecler procurou, desde o seu início, atuar junto a um público de menor poder aquisitivo, vinculado de um modo geral ao consumo de gêneros musicais mais populares, como o da música sertaneja e regional. Nesse sentido, a empresa assumiu inicialmente duas importantes estratégias.

Em primeiro lugar, ela adotou como seu formato principal de distribuição o discos de $78 \mathrm{rpm}$. Foi uma decisão bastante significativa, já que ocorria em um momento em que os Long Plays (LP), com consideráveis vantagens tecnológicas em relação aos discos de $78 \mathrm{rpm},{ }^{4}$ já estavam presentes no mercado nacional. A opção pelo lançamento de discos de $78 \mathrm{rpm}$ pode até ter sido resultado do acordo de Cássio Muniz com a RCA, que, naquele momento, estava concentrando suas atividades na produção de LP e podia, desse modo, repassar seus equipamentos obsoletos à Chantecler, mas não tenho nenhuma comprovação de que isso de fato tenha acontecido.

De qualquer modo, é preciso ressaltar que essa divisão entre os LP e os discos de $78 \mathrm{rpm}$ foi também uma marca do momento de estratificação então 
vivido pelo mercado fonográfico, que passava a ser constituído, de um lado, por consumidores de maior poder aquisitivo que podiam dispor dos novos equipamentos de reprodução e dos discos de vinil, e, de outro, daqueles que ainda se mantinham vinculados ao já obsoleto formato de $78 \mathrm{rpm}$. Além disso, vale observar que o surgimento dos LP também abriu novas possibilidades de promoção dos artistas: enquanto os discos de $78 \mathrm{rpm}$, assim como os compactos (singles), traziam apenas uma música em cada face e dependiam do sucesso da música para a venda, os LP traziam várias músicas e, desse modo, permitiam uma promoção mais focada na valorização do artista e na ideia do disco como uma obra autoral. ${ }^{5}$

Por essa razão, a empresa gravava uma média de quarenta discos de 78 rpm por mês contra 5 a 6 LP (depoimento de Baccarin, 1999). Para Baccarin, esse número expressivo de gravações tinha como objetivo formar catálogo para a gravadora - uma dificuldade adicional enfrentada pelas empresas nacionais, que tinham poucas oportunidades de distribuir catálogos importados e precisavam, por isso, assegurar rapidamente a posse de um número de títulos que garantisse sustentação de suas vendas. Assim, a Chantecler já surgia estabelecendo-se no nicho de mercado que, como já foi discutido aqui, seria menos explorado pelas grandes gravadoras internacionais e pela televisão.

Fortalecendo essa opção, um segundo aspecto da estratégia inicial da Chantecler foi a contratação de Diogo Mulero, o "Palmeira" da dupla Palmeira e Biá, como seu primeiro diretor artístico. A dupla lançara um pouco antes o seu maior sucesso, o bolero "Boneca cobiçada" (RCA, 1956). Assim, a gravadora demostrava, também através dessa contratação que pretendia uma atuação mais próxima da música popular romântica e do gênero sertanejo.

Segundo Baccarin, o primeiro disco da empresa foi lançado em 1958 e era um LP da orquestra de Zico Mazagão, que gravou "Cabecinha no ombro" e outros sucessos da época. O segundo disco foi Cascata de valsas, de Alberto Calçada, só com valsas brasileiras. Logo, a Chantecler obteve seus primeiros grandes sucessos com artistas como Cláudio de Barros (Cinzas do passado, 1959), Leila Silva (Perdão para dois, 1960), Edith Veiga (Faz-me rir, 1960), Marta Mendonça (Tu sabes, 1961), Luiz Wanderley (Baiano burro nasce morto, 1960), José Orlando (Somente tu, 1960), Wilson Miranda (Longe de ti, 1959) e o harpista paraguaio Luis Bordon, cujo primeiro trabalho para a gravadora foi o LP Nostalgias del Paraguay (1961).

Gravariam seus primeiros trabalhos pela Chantecler nomes como Waldick Soriano (1960) e Francisco Petrônio (1961). Outro artista de destaque da gravadora em sua fase inicial foi Poly, nome artístico do multi-instrumentista Ângelo Apolônio.

Mas o maior sucesso da história da gravadora parece ter sido, sempre segundo Baccarin (1999), "Coração de luto", gravação do gaúcho Teixeirinha, de 1959, que vendeu mais de 600 mil cópias. 
Apesar dos sucessos obtidos, a relação de Palmeira com a gravadora durou pouco mais de dois anos. Devido a um desentendimento financeiro com a direção da empresa ele deixa a direção artística em 1961, sendo substituído por Natal César. Mas esse não conseguiu se consolidar no cargo, que passou a ser ocupado por Biaggio Baccarin já no ano seguinte. Baccarin era funcionário do grupo Cássio Muniz desde 1951 e, em razão do seu grande interesse por música, passara a trabalhar na gravadora pouco depois de sua criação. Foi dele, por exemplo, a sugestão para a gravação, em 1959, no primeiro aniversário da Chantecler, da versão integral da ópera $O$ guarani, de Carlos Gomes, que foi lançada num pacote com três discos. Segundo Baccarin, nenhuma gravadora da América Latina havia, até então, registrado uma ópera ao vivo e O guarani jamais fora gravada integralmente. ${ }^{6}$ Os discos esgotaram-se rapidamente e foi o sucesso dessa iniciativa que acabou gerando o convite para que Baccarin se transferisse para a gravadora.

Ainda assim, a principal área de atuação da Chantecler foi mesmo a da música sertaneja, na qual teve entre seus primeiros contratados nomes como Tibagi e Miltinho (com gravações de 1960 a 1970), Tião Carreiro e Pardinho (a partir de 1963), Zico e Zeca (1959 a 1968), Pedro Bento e Zé da Estrada (1960 a 1963), Palmeira e Biá (1958 a 1961), Zé Bettio (1958 a 1964) e Mário Zan (a partir de 1958).

Baccarin destaca, entre os artistas que gravaram pela Chantecler a partir de sua atuação na direção artística, as cantoras Dominique (1962 a 1969), Giane (1962 a 1969), Joelma Giro (1963 a 1969) e Nalva Aguiar (1967 a 1968), o cantor José Augusto (1962 a 1969) e as duplas Lorenço e Lorival (a partir de 1967), Milionário e José Rico (a partir de 1973) e César e Paulinho (1978). Foi dele também a iniciativa de contratar os Demônios da Garoa - que passavam por um momento de baixa na carreira ${ }^{7}$ - e sugerir-lhes que gravassem um LP apenas com composições de Adoniran, inclusive a ainda inédita "Trem das onze" (1964), que se tornaria o maior sucesso do carnaval daquele ano.

O músico e pesquisador Roberto Correa, por sua vez, destaca a atuação de Baccarin no registro e preservação da música tradicional, citando, entre outros exemplos, a série de Folclore Brasileiro da Chantecler, idealizada por ele e inaugurada com o LP A verdadeira quadrilha de São João (1965), que apresenta temas folclóricos recolhidos por Rossini Tavares de Lima e Oneyda Alvarenga e interpretados por Alberto Calçada (Correa, 2012, p.88).

Desse modo, nas palavras de Baccarin (2007), a Chantecler

[...] acabou sendo uma gravadora do Rio Grande do Sul, uma gravadora do Norte-Nordeste, uma gravadora do Brasil Central, uma gravadora de São Paulo e um pouco Rio de Janeiro. No Rio de Janeiro ela entrava pouco, apesar de ter alguns artistas que fizeram sucesso lá. Então, pra mudar essa linha aí era muito complicado, então nós continuamos navegando nesse mesmo mar. 
Assim, ela se aproximou do perfil da Continental, tornando-se também uma gravadora que, para retomarmos a expressão de Pena Schmidt, "trabalha com o Brasil do lado de lá da Marginal Pinheiros".

\section{Crise e venda da gravadora}

Mas a passagem de Baccarin pela direção artística da Chantecler ocorreu num momento delicado para o grupo Cássio Muniz, que perdia as representações de importantes empresas internacionais e ficava cada vez mais limitado ao mercado de varejo. Com isso, o lucro obtido pela Chantecler acabava sendo utilizado para cobrir prejuízos de outras empresas do grupo, o que criava graves problemas para a manutenção de seu elenco. Como consequência, nomes fundamentais como Teixeirinha e Cláudio de Barros, entre outros, acabaram deixando a Chantecler no final dos anos 1960.

Uma desavença entre os sócios levou, em 1970, à separação da Chantecler do grupo Cássio Muniz. Nesse período, a empresa chegou a distribuir no Brasil o catálogo da gravadora norte-americana MCA. Mas os problemas financeiros persistiam e, em 1972, a Chantecler acabou vendida para a Continental (depoimento de Baccarin, 1999).

Segundo Baccarin, essa foi em princípio uma boa solução para a gravadora. Sua estrutura administrativa foi mantida e ela funcionava na Rua Aurora, no centro de São Paulo, enquanto a Continental tinha suas operações na Avenida do Estado. Nesse período, além de gravar novos nomes de sucesso como Belchior (1973 a 1974) e Luiz Américo (1973 a 1977), a Chantecler teve a já citada dupla Milionário e José Rico como seu carro-chefe. Porém, na segunda metade dos anos 1970, a própria Continental acabou atingida pela crise econômica que se avolumava e, como medida de redução de custos, integrou a Chantecler à sua estrutura administrativa em 1978. Assim, a empresa deixou formalmente de existir transformando-se em uma marca (selo) da Continental.

Em 1981, o nome da gravadora ainda surgiu com força através do show "A Grande Noite da Viola", concebido por Baccarin. Realizado em 20 de junho de 1981, o evento reuniu, em pleno Maracanãzinho, Rio de Janeiro, grandes estrelas da música sertaneja, como Tonico e Tinoco, Cascatinha (Inhana havia falecido dias antes), Vieira e Vieirinha, Milionário e José Rico, Tião Carreiro e Pardinho, Irmãs Galvão, Berenice Azambula e Teixerinha, entre outros. O show foi uma promoção conjunta da Chantecler e da Rádio Nacional. Com cobertura da TVS (Jornal do Brasil, 1981) o evento reuniu, segundo Baccarin, um público de aproximadamente 15 mil pessoas.

Entendo que "A Grande Noite da Viola" poderia ser vinculada a um momento inicial de penetração da música sertaneja junto ao público urbano. Entre outros exemplos, vale citar o lançamento, em 1979, do filme Estrada da vida, de Nelson Pereira dos Santos, estrelado pela dupla Milionário e José Rico, e o sucesso da série televisiva Carga pesada, da Rede Globo, que, lançada no mesmo ano, reunia em sua trilha sonora nomes da música sertaneja e nordestina como 


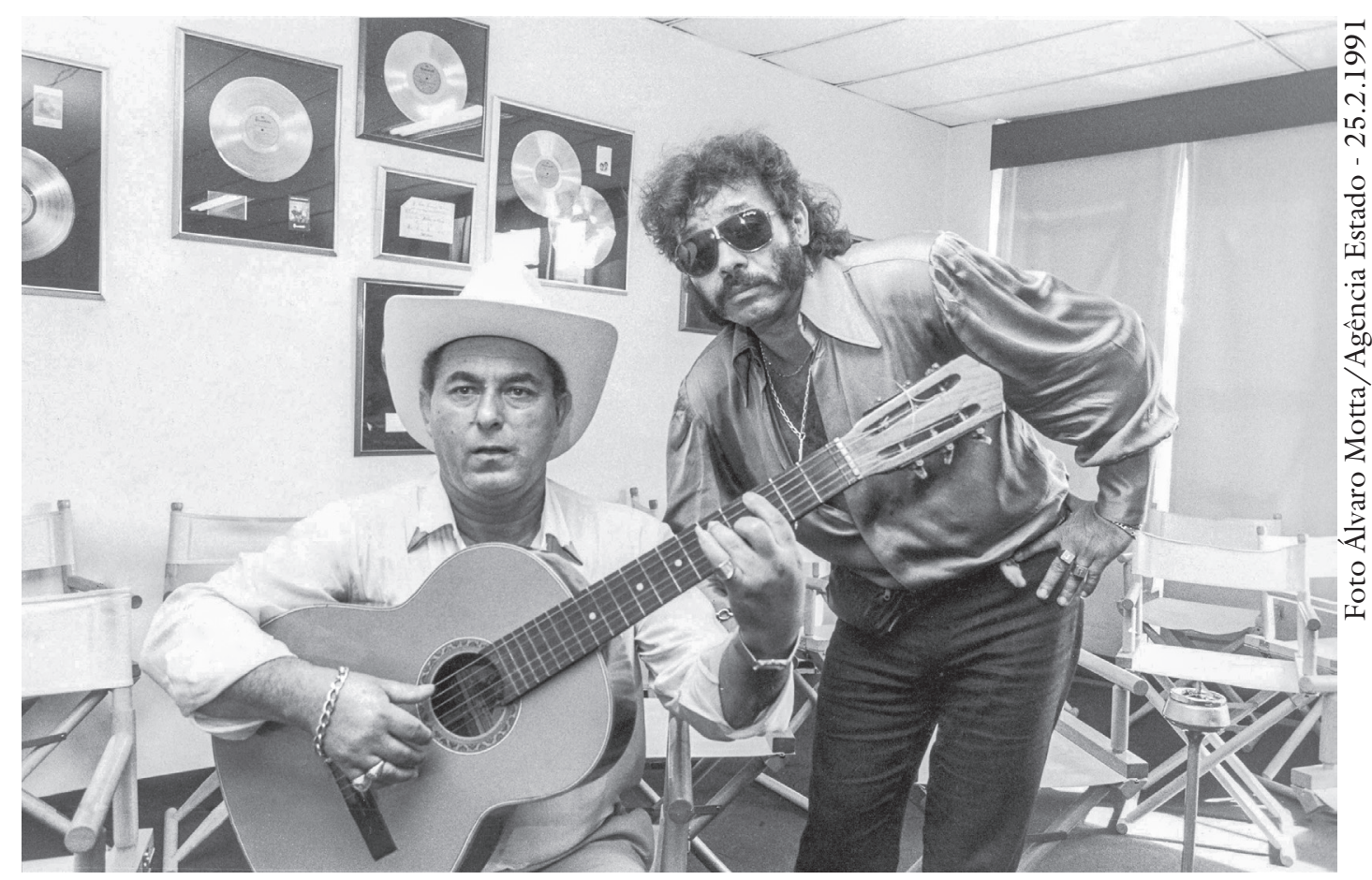

A dupla Milionário e José Rico no escitório da gravadora em São Paulo

Leo Canhoto e Robertinho, Rock e Ringo, Sérgio Reis, Renato Teixeira, Dominguinhos e Luiz Gonzaga, entre outros. Esse processo alcançaria seu ápice no início da década seguinte, quando a música sertaneja se tornaria o segmento de maior sucesso da indústria através de nomes como Chitãozinho e Xororó, Leandro e Leonardo, Zezé de Camargo e Luciano, João Paulo e Daniel, entre outros. Deve-se destacar que todos eles iniciaram suas carreiras em gravadoras nacionais.

Sempre segundo Baccarin (1999), "A Grande Noite da Viola" foi o último momento de maior visibilidade da marca Chantecler, que foi gradualmente abandonada pela Continental. Em 1994, a própria Continental foi vendida, transformando-se em parte da Warner Music que, mesmo nos relançamentos de fonogramas do catálogo da Chantecler, acabou por não resgatar o nome do selo.

Baccarin, que se tornara gerente de produtos da Continental quando a Chantecler foi integrada à sua estrutura, saiu da empresa em 1981, mas acabou mantendo um relacionamento com a gravadora na condição de advogado especializado em direitos autorais, área em que atuou até pelo menos o final da década de 2000.

\section{Conclusão}

Gravadoras nacionais como a Chantecler foram as responsáveis por um trabalho fundamental de documentação da música popular brasileira, registrando os trabalhos de artistas populares, muitos deles vinculados à música regional, num momento em que as grandes empresas do setor praticamente ignoravam 
a existência desse mercado. Assim, atuaram junto a gêneros musicais como o sertanejo, por exemplo, que só seriam privilegiados pela atuação das grandes gravadoras internacionais (majors) a partir da década de 1990, quando a substituição do LP pelo CD não apenas propiciou um extraordinário crescimento do mercado, como tornou menos significativa a variação de preços dos discos.

Desse modo, entendo que o vigoroso processo de regionalização da música do país, verificado a partir dos anos 1990, só foi possível a partir do trabalho anterior dessas gravadoras na promoção de artistas e na prospecção de cenas locais. A já citada venda da Continental para a Warner, a incorporação do acervo da Copacabana pela EMI no mesmo período, bem como a contratação de artistas formados nessas empresas por parte de grandes gravadoras - caso de praticamente todos os nomes da música sertaneja dos anos 1990 - parecem-me confirmar essa hipótese.

Também por conta disso, é importante um esforço no sentido tanto da recuperação da memória dessas empresas quanto de seus acervos musicais, já que uma significativa parcela do repertório de gravadoras como Continental, Copacabana e Chantecler, entre muitas outras, provavelmente jamais foi digitalizada.

\section{Notas}

1 Este artigo representa a versão ampliada e bastante modificada de texto publicado na edição n.87 (2010) da Revista da USP sob o título "Chantecler: uma gravadora popular paulista", disponível em <http://www.revistas.usp.br/revusp/issue/view/1088>.

2 Acervo Aramis Millarch, Dispon'[ivel em: <http://www.millarch.org/artigo/continental-sua-historia-gravada-fundo-dentro-da-mpb>. Acesso em: 20 jun. 2017.

3 Disponível em <http://www.millarch.org/audio/capitão-furtado>. Acesso em: 14 jun. 2017.

4 Os LP, feitos em vinil e com rotação de $33.1 / 3 \mathrm{rpm}$, tinham sido lançados no mercado norte-americano ainda nos anos 1940, e os primeiros a serem gravados no Brasil surgiram no início da década seguinte. Eles apresentavam um nível de ruído menor e a capacidade de reproduzir um leque de frequências muito mais amplo do que os discos de 78 rpm, o que tornava seu som mais aberto e próximo ao das apresentações ao vivo. Também permitiram a gravação de várias músicas nos 20 minutos (em média) comportados em cada uma de suas faces, enquanto os discos de $78 \mathrm{rpm}$ apenas comportavam três a quatro minutos de áudio, a duração média de uma música. Adicionalmente, o LP podia reproduzir sons estereofônicos, enquanto os discos de $78 \mathrm{rpm}$ eram monofônicos.

5 Discuto de forma mais detalhada essa questão em Vicente $(2014$, p.59 ss.).

6 Sempre segundo Baccarin, a gravação foi feita pela Orquestra Sinfônica Municipal de São Paulo sob a regência de Armando Belardi. O elenco de cantores era o da Rádio Gazeta. Essa gravação foi utilizada durante muito tempo para a abertura do programa A hora do Brasil.

7 O disco anterior do grupo no Brasil era de 1961 e havia sido lançado pela Imperial Discos. 


\section{Referências}

CONTIER, A. O Nacional na Música Erudita Brasileira: Mário de Andrade e a Questão da Identidade Cultural. Fênix - Revista de História e Estudos Culturais, v.1, ano 1, n.1, p.1, 2004. Disponível em: <www.revistafenix.pro.br/pdf/Artigo\%20Arnaldo\%20 Daraya\%20Contier.pdf>.

CORRÊA, R. Os primórdios dos discos comerciais da música tradicional brasileira. Novos Olhares, v.1, n.2, p.84-9, 2012.

FERRETE, J. L. Capitão Furtado: viola caipira ou sertaneja? Rio de Janeiro: Minc/ Funarte, 1985.

FRANCESCHI, H. A Casa Edison e seu tempo. São Paulo: Sarapuí, 2002.

GAZETA MERCANTIL. Quando a solução é mudar de gênero. Gazeta Mercantil, 4.12.1979, p.D5.

GIRON, L. A. Um império musical no Brasil. Gazeta Mercantil, Caderno Fim de Semana, 5-7.11.1999, p.2.

GUERRINI JUNIOR, I. A elite no ar-Óperas, Concertos e Sinfonias na Rádio Gazeta de São Paulo (1943-1960). São Paulo: Fapesp; Terceira Margem, 2009.

JORNAL DO BRASIL. Sertanejos desembarcam no Maracanãzinho. Jornal do Brasil, 12.6.1981, p.4.

NAPOLITANO, M. Seguindo a canção: engajamento político e indústria cultural na MPB (1959-1969). Versão digital revisada pelo autor. Disponível em: <https://www. academia.edu/3821530/SEGUINDO_A_CANCAO_digital>, 2010.

ORTIZ, R. Cultura brasileira e identidade nacional. 4.ed. São Paulo: Brasiliense, 1994.

PAIANO, E. Warner recupera acervo histórico de MPB da Continental. O Estado de $S$. Paulo, 25.10.1993, p.E3.

REIS, N. I. Remixando Teixeirinha. Uma análise antropológica sobre a construção da imagem pública do "Gaúcho Coração do Rio Grande". 2010. Tese (Doutorado em Antropologia Social) - Universidade Federal do Rio Grande do Sul. Porto Alegre, 2010.

SAROLDI, L. C.; MOREIRA, S. V. Rádio Nacional: o Brasil em sintonia. 3.ed. Rio de Janeiro: Jorge Zahar Editor, 2005.

TINHORÃO, J. R. Música popular: do gramofone ao rádio e TV. São Paulo: Ática, 1981.

VICENTE, E. Da vitrola ao iPod: uma história da indústria fonográfica no Brasil. São Paulo: Alameda, 2014.

VICENTE, E.; DE MARCHI, L. Por uma história da indústria fonográfica no Brasil 1900-2010: uma contribuição desde a Comunicação Social. Música Popular em Revista, Campinas, ano 3, v.1, p.7-36, jul.-dez. 2014.

VICENTE, E.; DE MARCHI, L.; GAMBARO, D. O rádio musical no Brasil: elementos para um debate. In: ZUCULOTO, V.; LOPEZ, D.; KISCHINHEVSKY, M. Estudos radiofônicos no Brasil: 25 anos do Grupo de Pesquisa Rádio e Mídia Sonora da Intercom. São Paulo: Grupo de Pesquisa Rádio e Mídia Sonora Intercom, 2016. p.457-76. 


\section{Depoimentos}

BACCARIN, B. Depoimento concedido ao autor em 11 de fevereiro de 1999.

BACCARIN, B. Depoimento concedido ao autor em 8 de junho de 2007.

SCHMIDT, P. Depoimento concedido ao autor em 14 de setembro de 2007.

RESUMO - Este texto busca apresentar a trajetória da gravadora paulistana Chantecler que, desde sua criação, em 1958, teve um papel fundamental na produção de discos de artistas ligados à música regional brasileira, especialmente à música sertaneja. Até os anos 1990, tais gêneros musicais tendiam a ser menosprezados pelas gravadoras internacionais instaladas no país. O texto busca ainda refletir acerca do processo de estratificação do consumo de música popular que se verifica no país a partir dos anos 1960 e, nesse contexto, do papel que passa a ser ocupado pelas gravadoras nacionais diante das grandes empresas internacionais (majors) instaladas no país. Desse modo, o texto busca contextualizar a atuação da Chantecler dentro do cenário mais amplo da indústria fonográfica do Brasil.

PALAVRAs-Chave: Música Popular Brasileira, Indústria fonográfica, Música sertaneja, Gravadora Chantecler.

ABSTRACT - The article recovers the history of the Brazilian record label Chantecler, founded in 1958 and based in São Paulo, which played a crucial role in the production of Brazilian regional music, especially Brazilian sertaneja music. Until the 1990s, regional music genres were mostly disregarded by major international record companies operating in Brazil. From that perspective, this work discusses the stratification of popular music consumption in Brazil after the 1960s, noting the role of domestic vis-à-vis international record labels, and thus contextualizes the presence of Chantecler in the broader scenario of the national record industry.

KEYWORDS: Brazilian popular music, Record industry, Brazilian country music, Chantecler record label.

Eduardo Vicente é professor associado do Departamento de Cinema, Rádio e TV da Escola de Comunicações e Artes da USP, e do Programa de Pós-Graduação em Meios e Processos Audiovisuais da ECA-USP, coordenador do MidiaSon: Grupo de Estudos e Produção em Mídia Sonora. @- eduvicente@usp.br

Recebido em 7.7.2017 e aceito em 27.7.2017.

${ }^{\text {I }}$ Departamento de Cinema, Rádio e TV, Escola de Comunicação e Artes, Universidade de São Paulo, São Paulo, São Paulo, Brasil. 